\title{
Digit-sucking habit of preschool children in Enugu, Eastern Nigeria
}

\author{
Samuel N. Uwaezuoke ${ }^{1}$, Gideon C. IIechukwu ${ }^{2}$, Henrietta U. Okafor ${ }^{2}$ \\ ${ }^{1}$ Institute of Child Health, University of Nigeria Teaching Hospital Enugu, Nigeria \\ ${ }^{2}$ Department of Pediatrics, University of Nigeria Teaching Hospital Enugu, Nigeria
}

\begin{abstract}
Although digit-sucking habit is common in preschool children, there is multiracial variation of prevalence rates. Hitherto unidentified variables are being reported as possible risk factors. To analyse this habit in preschool children in Enugu, Eastern Nigeria, a prospective crosssectional study was conducted on one hundred (100) children. Their mothers were interviewed with a structured questionnaire. The habit was noted in $23 \%$ of the children, with a slight male preponderance. Using the correlation coefficient model, longer total duration of breast-feeding was not well correlated with increase in number of digit-sucking preschool children (correlation coefficient, $r=0.36, P<0.05)$. The number of these children exposed to pacifier sucking was significantly greater than the number of their non-sucking counterparts with similar exposure $\left(\chi^{2}=38.56, P<0.05\right)$. It is concluded that preschool children exposed to pacifier use and shorter duration of breast-feeding were more likely to exhibit the habit. (J Pediatr Neurol 2003; 1(2): 99-101).
\end{abstract}

Key words: digit-sucking, habit, preschool children, prevalence, risk factors.

\section{Introduction}

Digit-sucking habit is a common behaviour disorder in early childhood which often serves as an outlet for emotional distress or boredom (1-3). The

Correspondence: Dr. Samuel N. Uwaezuoke Institute of Child Health

U.N.T.H. Enugu, Nigeria

Tel: 023433248 108, fax: 023492726161 .

E-mail: snuwaezuoke@yahoo.com

Received: May 26, 2003

Accepted: July 16, 2003. prevalence however varies in different races and cultures (4). Although a harmless habit, complications of its persistence include dental malocclusion, callosities, ulcers, and rotation of thumb (3), as well as reduced peer social acceptance (5). Interestingly, some studies have reported that the habit frequently accompanies other behaviour like holding or manipulating favoured objects (6), and has reverse association with pacifier sucking (7). Bottle-feeding was also noted to be a risk factor (8). The purpose of this study is to document the prevalence and potential risk factors in preschool children from a Nigerian population.

\section{Subjects and Methods}

\section{Study population and inclusion criteria}

The study population was composed of underfive children brought for medical consultation at the children's out-patient clinic of the University of Nigeria Teaching Hospital in Enugu, Eastern Nigeria. Subjects were recruited if they were 12 to 60 months of age, living with biological parents, and had no physical, mental or social handicap.

\section{Sampling and study design}

One hundred preschool children (with equal gender representation) were selected by systematic sampling from the list of children attending the clinic on the days of study. After informed consent, data was collected from mothers using an interviewer-administered structured questionnaire comprising open-ended questions on child's age, parent's educational status/occupation, family size, subject's rank among siblings, type of infant feeding from birth, breast-feeding duration, history of pacifier sucking, onset of digit-sucking habit (if present at the time of data collection) as well as closed-ended questions on the specific digits sucked and the observed aggravating factors.

\section{Data analyses}

Data entry and analysis were carried out with EPI-INFO Version 5 computer package. Using 
Table 1. Demographics of the children

\begin{tabular}{ll}
\hline $\begin{array}{l}\text { Age ranges } \\
\text { (month) }\end{array}$ & $\begin{array}{c}\text { Total }(\mathbf{n = 1 0 0 )} \\
\mathbf{n}(\%)\end{array}$ \\
\hline $12-22$ & $29(29)$ \\
$23-32$ & $25(25)$ \\
$33-42$ & $24(24)$ \\
$43-52$ & $16(16)$ \\
$53-62$ & $6(6)$ \\
\hline Parent's social classes & $\mathbf{n}(\%)$ \\
\hline I & $17(17)$ \\
II & $26(26)$ \\
III & $26(26)$ \\
IV & $29(29)$ \\
V & $2(2)$ \\
\hline
\end{tabular}

the chi-squared test to assess whether the number of digit-sucking and non-sucking children were significantly influenced by exposure to pacifier use, the adopted level of significance was 0.05.

A correlation coefficient model was used to determine if any linear relationship existed between longer total duration of breast-feeding and increase in number of digit-sucking children.

\section{Results}

\section{Demographics}

The subjects' ages ranged from 12 to 60 months (mean $\pm \mathrm{SD} ; 31.8 \pm 12.5$ months), with majority $(78 \%$ ) falling within 12 to 42 month age-bracket (Table 1). Using Oyedeji's social classification method (9) they were distributed according to parental social class as follows; 17 (I); 26 (II); 26 (III); 29 (IV) and 2 (V).

\section{Prevalence}

At the time of study, only $23 \%$ of the children habitually sucked their fingers, with a slight male preponderance (male/female ratio; 1.3/1). They were substantially represented in the upper i.e I and II (48\%) and lower i.e IV and V (35\%) social classes. The onset of habit was before 3months of age in about $74 \%$ of the children. Majority of these digit-sucking children were aged between 12 and 32 months (mean \pm SD; $29 \pm 12.8$ months) (Figure 1).

\section{Digit-sucking habit vs. pacifier sucking}

Out of the 23 digit-sucking preschool children, $6(26 \%)$ were exposed to pacifier use. Among their 77 counterparts who did not exhibit the habit, only $2(2.6 \%)$ were similarly exposed. The difference between the two groups was statistically significant. $\left(\chi^{2}=38.56, \mathrm{P}<0.05\right)$. Therefore, digit-sucking habit is more likely to be associated with previous exposure to pacifier-sucking.

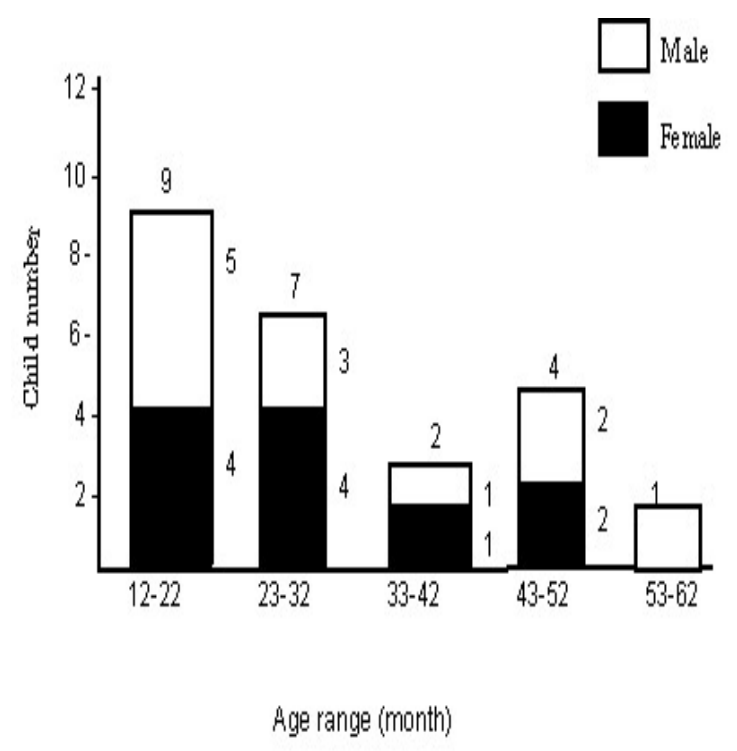

Figure 1. Age-range of the digit-sucking preschool children.

\section{Digit-sucking habit vs. breast-feeding duration}

Only $5(22 \%)$ of the 23 digit-sucking preschool children were breastfed for more than 12 months while 18 (78\%) had breast-feeding for 12 months or less. Using the correlation coefficient model, it was noted that longer total breast-feeding duration was not well correlated with increase in the number of preschool children who sucked their digits. (correlation coefficient, $r=0.36$ ). Thus, longer total duration of breast-feeding may significantly lower the prevalence of the habit in children.

\section{Specific digits sucked}

Analysis indicated that $14(61.0 \%)$ sucked the thumb alone; 7 (30.4\%) index and middle fingers together; 1 (4.3\%) middle finger alone while 1 $(4.3 \%)$ sucked the ring and middle fingers together. The most frequently observed aggravating factor for the habit was boredom (74\%).

\section{Discussion}

The prevalence rate of $23 \%$ noted in this study compares favourably with $17 \%$ among Indian children and 30\% among Swedish children (4). It differs considerably from as low as $1 \%$ in Eskimo children (4). Admittedly, the figure reported in this study is preliminary because a larger sample size should have been studied to document a more representative prevalence rate. The slight male preponderance and the occurrence of habit in children, from both upper and lower social classes in a metropolitan setting, agree with the findings of other workers in Calcutta, India (8). Zadik et al (7) however reported no gender difference. In our study, the mean age of digit-sucking preschool children was $29 \pm 13$ months which underscores 
the previously documented fact that the habit resolves spontaneously by the 4th birthday (10). We also observed that the habit was more likely to be associated with previous exposure to pacifier sucking and shorter total duration of breast-feeding. These findings contradict the reverse association between the habit and pacifier sucking reported by Zadik et al (7), as well as its non-existent association with total duration of breast-feeding $(7,11)$. Pacifier use has been suggested as a substitute of choice for thumb-sucking and thus a veritable tool for habit reversal (7). This view is supported by Christensen and Sanders (12) who observed that habit reversal (H.R) and differential reinforcement of other behaviour (D.R.O) effectively reduced thumb sucking. Nevertheless, our finding can be explained by the fact that since both habits seem to provide extra self-nurturance to the child understimulated by human touch (2), digit-sucking easily becomes an adaptable habit in stressful situations for a child previously exposed to pacifier use.

It is not surprising that shorter total duration of breast-feeding can predispose to digit sucking since breast-feeding fosters close maternal and child bonding, as well as emotional satisfaction for both mother and child (13). To further buttress this fact, other workers have reported that bottle-feeding is a major predisposing factor (8).

In conclusion, longer total duration of breastfeeding and avoiding the use of pacifier could reduce the prevalence of this habit in children. A follow-up community-based study is recommended in this locality for a more representative result.

Study limitations

1. Small sample size

2. Study was not observational but based on mothers' power of recall.

Acknowledgement

We are indebted to the pediatric interns who helped in data collection, the nursing staff for their supportive role, and Mrs. N. Jude-Ejekam for her excellent secretarial work.

\section{References}

1. Robinson MJ. Some common behavioural disturbances in children. In : Robinson MJ, Lee EL (eds). Paediatric Problems in Tropical countries (1st ed). Edinburgh: Churchill Livingstone, 1978, pp 912.

2. Dalton R, Forman MA. Psychosocial problems. In: Behrman RE, Kliegman RM, Jenson HB (eds). Textbook of Pediatrics (16th ed). Philadelphia: WB Saunders, 2000, p 69.

3. Rendle-Short J, Gray OP, Dodge JA. A Synopsis of Children's Diseases. (6th ed). Bristol: John Wright \& Sons Ltd, 1985.

4. Curzon ME. Dental implications of thumb-sucking. Pediatrics 1974; 54: 196-200.

5. Friman PC, McPherson KM, Warzak WJ, Evans J. Influence of thumb-sucking on peer social acceptance in first-grade children. Pediatrics 1993; 91: 784-786.

6. Friman PC. Eliminating chronic thumb-sucking by preventing a covarying response. J Behav Ther Exp Psychiatry 1988; 19: 301-304.

7. Zadik D, Stern N, Litner M. Thumb- and pacifiersucking habits. Am J Orthod 1977; 71: 197-201.

8. Sarkar S, Chowdhury KS, Mukherjee MM. Prevalence of thumb-sucking in children of Calcutta. J Indian Soc Pedod Prev Dent 1992; 10: 33-36.

9. Oyedeji GA. Socioeconomic and cultural background of hospitalized children in Ilesha. Nig J Paediatr 1985; 12: 111-117.

10. Gilbertson NJ. Behaviour disorders and childhood psychiatry. In: Gilbertson NJ, Walker SJ (eds). Notes for the DCH. London: Churchill Livingstone, 1993, p 114.

11. Aarts C, Hörnell A, Kylberg E, Hofvander Y, GebreMedhin M. Breast feeding patterns in relation to thumb-sucking and pacifier use. Pediatrics 1999; 104: e50.

12. Christensen AP, Sanders MR. Habit reversal and differential reinforcement of other behaviour in the treatment of thumb-sucking: an analysis of generalization and side-effects. J Child Psychol Psychiatry 1987; 28: 281-295.

13. Kaine W. Baby Care - A Handbook for Mothers and Health-Care Students (3rd ed). London: Macmillian, 1988. 